\title{
Care Transitions From Patient and Caregiver Perspectives
}

Suzanne E. Mitchell, MD, MS

Vivian Laurens, MA

Gabriela M. Weigel

Karen B. Hirschman, PbD, MSW

Allison M. Scott, PbD, MA

Huong Q. Nguyen, PbD, RN

Lance Laird, TbD, MDiv

Carol Levine, MA

Terry C. Davis, PbD

Brianna Gass, MPH

Elizabeth Shaid, MSN

Jing Li, MD, MS

Mark V. Williams, MD

Brian W. Jack, MD
Jessica Martin Howard, MA, MPH

\begin{abstract}
PURPOSE Despite concerted actions to streamline care transitions, the journey from hospital to home remains hazardous for patients and caregivers. Remarkably little is known about the patient and caregiver experience during care transitions, the services they need, or the outcomes they value. The aims of this study were to (1) describe patient and caregiver experiences during care transitions and (2) characterize patient and caregiver desired outcomes of care transitions and the health services associated with them.
\end{abstract}

METHODS We interviewed 138 patients and 110 family caregivers recruited from 6 health networks across the United States. We conducted 34 homogenous focus groups (103 patients, 65 caregivers) and 80 key informant interviews (35 patients, 45 caregivers). Audio recordings were transcribed and analyzed using principles of grounded theory to identify themes and the relationship between them.

RESULTS Patients and caregivers identified 3 desired outcomes of care transition services: (1) to feel cared for and cared about by medical providers, (2) to have unambiguous accountability from the health care system, and (3) to feel prepared and capable of implementing care plans. Five care transition services or provider behaviors were linked to achieving these outcomes: (1) using empathic language and gestures, (2) anticipating the patient's needs to support self-care at home, (3) collaborative discharge planning, (4) providing actionable information, and (5) providing uninterrupted care with minimal handoffs.

coNCLuSIONS Clear accountability, care continuity, and caring attitudes across the care continuum are important outcomes for patients and caregivers. When these outcomes are achieved, care is perceived as excellent and trustworthy. Otherwise, the care transition is experienced as transactional and unsafe, and leaves patients and caregivers feeling abandoned by the health care system.

Ann Fam Med 2018;16:225-231. https://doi.org/10.1370/afm.2222.

\section{INTRODUCTION}

$\mathrm{D}$ espite concerted actions to streamline care transitions, the journey from hospital to home remains hazardous and frustrating for many patients and caregivers, suggesting gaps still exist between

Conflicts of interest: S.E.M. is a non-product speaker for Merck \& Co. M.V.W. bas received grant and contract funding from the Patient-Centered Outcomes Research Institute, AHRQ, BlueCross BlueShield of Illinois, and has received royalty payments from Elsevier for the reference text book Comprebensive Hospital Medicine. To the best of our knowledge, no other conflicts of interest, financial or other, exist for any of the authors.

\section{CORRESPONDING AUTHOR}

Suzanne E. Mitchell, MD, MS

Department of Family Medicine

Boston Medical Center/Boston University

School of Medicine

1 Boston Medical Center Place

Boston, MA 02118

suzanne.mitchell@bmc.org the services provided and services needed for a person to successfully navigate a care transition. In research trials, multifaceted care transition interventions have been shown to improve patient experiences and reduce avoidable readmissions. ${ }^{1-5}$ However, efforts to disseminate these programs to real world settings have achieved mixed results. ${ }^{6-10}$ One reason may be the tendency for health systems to modify evidence-based interventions by clustering components from different protocols. ${ }^{11-13}$ These modified care transition protocols may be effective in conserving resources, but may be misaligned with essential needs of patients and caregivers. Little research has focused on the patient and caregiver experience during care transitions; consequently, the outcomes most important to them and the care transition services that best meets their needs remain unclear.

To address this knowledge gap, we implemented Project ACHIEVE (Achieving Patient-Centered Care and Optimized Health In Care Transitions by Evaluating the Value of Evidence $)^{14}$ in 2015, a study funded by the Patient-Centered Outcomes Research Institute to compare the effec- 
tiveness of different clusters of evidencebased care transition services in achieving the outcomes most relevant to patients and caregivers. To do this we designed a pilot study to identify the care transition outcomes most important to patients and care givers and used that information to create a conceptual model for how care transition services and provider behaviors are linked to achieving these outcomes. We report the findings of our pilot study that will serve as the foundation for Project ACHIEVE's national survey. The national survey will be administered to more than 10,000 patients, family caregivers, and health providers to determine which clusters of care transition services are most effective in achieving patient and caregiver desired outcomes.

\section{METHODS}

We conducted a qualitative study using focus groups and individual interviews with patients and their family caregivers. All participants provided informed consent and the institutional review boards for each of the sites approved the study protocol. Data were collected between March 1, 2015 and March 1, 2016.

\section{Sample and Recruitment}

We enrolled a total of 248 participants (138 patients, 110 family caregivers), of whom 168 participated in 34 homogeneous focus groups (103 patients, 65 caregivers) and 80 participated in key informant interviews (35 patients, 45 caregivers) (Table 1). Focus groups averaged 5 participants each.

Eligible participants were those with experience as a patient or as a primary caregiver who had experienced a care transition within 90 days of enrollment. Care transition was defined as an acute hospitalization followed by discharge to post-acute care at home or to a nursing facility for stabilization and/or recovery. Adult patients and family caregivers were recruited from 6 health care networks in 6 geographic regions of the United States (California, New England, Pennsylvania, Louisiana, Kentucky, Colorado) through electronic medical record queries, tele-
Table 1. Participant Demographics

\begin{tabular}{|c|c|c|c|}
\hline Characteristic & $\begin{array}{c}\text { Patient } \\
(\mathrm{n}=138), \\
\text { No. }(\%)\end{array}$ & $\begin{array}{c}\text { Caregiver } \\
(\mathrm{n}=110), \\
\text { No. }(\%)\end{array}$ & $\begin{array}{c}P \\
\text { Value }\end{array}$ \\
\hline Age & & & $<0.001^{\text {a }}$ \\
\hline Range & $20-90$ & $19-81$ & \\
\hline Average (Mean $\pm S D$ ) & $61.23 \pm 14.54$ & $55.67 \pm 11.88$ & \\
\hline Sex (missing $=1$ ) & & & $<0.001$ \\
\hline Male & $59(43.07)$ & $18(16.36)$ & \\
\hline Female & $78(56.93)$ & $92(83.64)$ & \\
\hline $\begin{array}{l}\text { Non-Hispanic racial breakdown } \\
(\text { missing }=3)\end{array}$ & & & $0.832^{\mathrm{b}}$ \\
\hline African American/black & $47(34.31)$ & $41(37.96)$ & \\
\hline White & 67 (48.91) & $52(48.15)$ & \\
\hline White and African American/black & $0(0.00)$ & $1(0.93)$ & \\
\hline Native Hawaiian/Pacific Islander & $1(0.73)$ & $0(0.00)$ & \\
\hline American Indian/Alaskan & $3(2.19)$ & $1(0.93)$ & \\
\hline Other & $19(13.87)$ & $13(12.04)$ & \\
\hline $\begin{array}{l}\text { Hispanic/Latino/Spanish origin } \\
\quad(\text { missing }=1)\end{array}$ & $25(18.25)$ & $22(20.00)$ & 0.727 \\
\hline Education level (missing $=1$ ) & & & $<0.001$ \\
\hline Did not start or finish high school & $59(43.07)$ & $16(14.55)$ & \\
\hline High school graduate or GED & $29(21.17)$ & $36(32.73)$ & \\
\hline Trade or vocational school & $5(3.65)$ & $8(7.27)$ & \\
\hline Some college or associates degree & $28(20.44)$ & $20(18.18)$ & \\
\hline College graduate (BA, BS) & $7(5.11)$ & $15(13.64)$ & \\
\hline Post-graduate degree & $9(6.57)$ & $15(13.64)$ & \\
\hline Employment (missing $=1$ ) & & & $<0.001^{\mathrm{b}}$ \\
\hline Full time & $3(2.19)$ & $36(32.73)$ & \\
\hline Part time & $5(3.65)$ & $8(7.27)$ & \\
\hline Retired & $50(36.50)$ & $29(26.36)$ & \\
\hline Disabled & $73(53.28)$ & 10 (9.09) & \\
\hline Unemployed or laid off & $3(2.19)$ & $15(13.64)$ & \\
\hline Other (homemaker, student, etc) & $3(2.19)$ & $12(10.91)$ & \\
\hline $\begin{array}{l}\text { Qualifies as low health literacy } \\
\text { (missing }=1 \text { ) }\end{array}$ & $60(43.80)$ & $26(23.64)$ & 0.0009 \\
\hline Marital status (Missing $=2$ ) & & & N/A \\
\hline Married & $41(30.15)$ & N/A & \\
\hline Divorced or separated & $31(22.79)$ & $\mathrm{N} / \mathrm{A}$ & \\
\hline Single without partner & $30(22.06)$ & $N / A$ & \\
\hline Single with partner & $11(8.09)$ & $N / A$ & \\
\hline Widowed & $23(16.91)$ & $N / A$ & \\
\hline Health insurance (missing $=1$ ) & & N/A & N/A \\
\hline Has Medicare & $135(98.54)$ & N/A & \\
\hline Has Medicaid & $93(67.88)$ & $N / A$ & \\
\hline Has Medicare \& Medicaid & $91(66.42)$ & $N / A$ & \\
\hline $\begin{array}{l}\text { Has } 3 \text { or more chronic conditions } \\
\text { (missing }=1 \text { ) }\end{array}$ & $103(75.18)$ & $N / A$ & N/A \\
\hline $\begin{array}{l}\text { Screened positive for depression (miss- } \\
\text { ing }=1 \text { ) (Score }>10 \text { on PHQ8) }\end{array}$ & $40(29.20)$ & $17(15.45)$ & 0.011 \\
\hline $\begin{array}{l}\text { Screened positive for anxiety (miss- } \\
\text { ing }=1)(\text { Score }>10 \text { on GAD7) }\end{array}$ & $35(25.55)$ & $23(20.91)$ & 0.393 \\
\hline \multicolumn{4}{|c|}{$\begin{array}{l}\mathrm{GED}=\text { general equivalency diploma; } \mathrm{BA}=\text { bachelor of arts; } \mathrm{BS}=\text { bachelor of science; } \mathrm{PHQ}=\text { per- } \\
\text { sonal health questionnaire; } \mathrm{GAD}=\text { general anxiety disorder. }\end{array}$} \\
\hline \multicolumn{4}{|c|}{ N/A indicates responses only provided by patient group. } \\
\hline \multicolumn{4}{|c|}{$P$ values calculated using the $\chi^{2}$ method unless noted. } \\
\hline $\begin{array}{l}\text { a } 2 \text { sided } t \text {-test } \\
\text { bFisher's exact test }\end{array}$ & & & \\
\hline
\end{tabular}


phone calls, and referrals. Snowball sampling was used to identify additional patients and caregivers. Low health literacy was confirmed based on responses to a 2 -item validated question set: How confident are you in filling out medical forms by yourself? and Do you usually ask someone to help you read materials you receive from the hospital? ${ }^{15}$ Low socioeconomic status was determined based on Medicaid eligibility.

\section{Data Collection}

Trained qualitative researchers conducted semistructured focus group interviews and key informant interviews in English and Spanish. Each focus group had a facilitator and a note taker. ${ }^{16}$ Researchers interviewed participants via telephone or at the patient bedside to increase participation among frail elders and those with physical disabilities. Interviews averaged 45 minutes duration while focus groups averaged 75 minutes in length and followed a semistructured interview guide. The guide questions (Table 2) were designed to elicit the outcomes of care most important to patients and caregivers and to identify the services that best supported achievement of these outcomes. Focus group discussions and individual interviews were audio recorded and transcribed. Interviews conducted in Spanish were transcribed in both Spanish and English. Data analysis was ongoing throughout the study period, and ended when new salient themes ceased to surface and data saturation was attained..$^{17,18}$

\section{Management and Analysis}

The core analysis team consisted of a family physician (S.E.M.), a medical anthropologist (L.L.), and a qualitative researcher (V.L.). Ten trained research assistants participated in data coding and analysis. We used an inductive approach to the data analysis to allow unanticipated themes and relationships to emerge. Data were deidentified and analyzed with NVivo 9 software (QSR International) using a multi-phased coding approach consistent with grounded theory. ${ }^{14}$ Focus group data were analyzed first and used to

\section{Table 2. Interview Guide Questions}

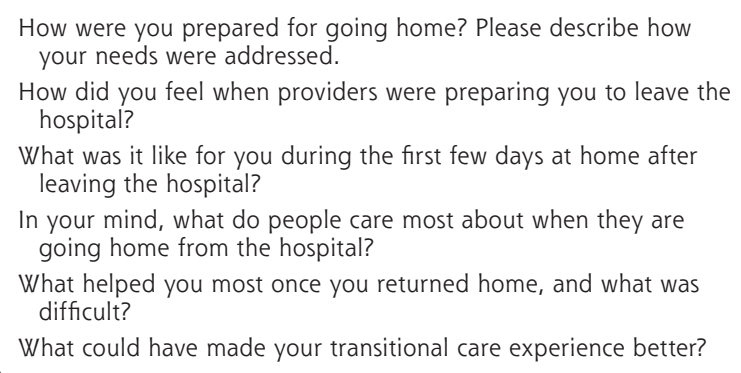

create an initial codebook using the grounded theory strategy of coding transcripts line by line, using code labels closely resembling participants' own words and phrasing, and adding new codes as needed. ${ }^{16,19,20}$ Each transcript was coded by 2 independent researchers using the code book. ${ }^{20}$ Coding discrepancies were resolved through negotiation with an expert qualitative researcher present. All coders wrote detailed analytical memos which were discussed to identify emerging themes and categories. A total of 194 initial codes were created and consolidated into 42 parent concept codes. These were then organized into 21 broader category codes and finally into 8 themes by group consensus using an axial coding approach. ${ }^{19}$

Commonalities and differences in perspective between patients and caregivers were analyzed using a constant comparative analysis approach. Parent and category codes were consolidated to create a conceptual model of care transition outcomes prioritized by participants and the processes of care aligned with each outcome (Figure 1). We considered alternative models to describe the relationship between themes. We validated our findings and conceptual model by presenting them to the Project ACHIEVE Stakeholder Advisory Group for their comments and suggestions.

\section{RESULTS}

Among patient participants, the average age was 61 years (range 20 to 90 years), 57\% were female, 30\% married, $18 \%$ Hispanic with $49 \%$ non-Hispanic white and $34 \%$ non-Hispanic black, $44 \%$ were low health literacy, $29 \%$ screened positive for depressive symptoms, all were Medicare beneficiaries, and $66 \%$ were insured by both Medicare and Medicaid. Caregiver participants were predominantly female (84\%) with an average age of 56 years (range 19 to 81 years), 24\% were low health literacy and $15 \%$ screened positive for depressive symptoms. Additional details are found in Table 1.

Participants identified 3 outcomes they believed to be integral to safe and manageable care transitions: (1) feeling cared for and cared about by medical providers, (2) having unambiguous accountability on the part of the health care system, and (3) feeling prepared and capable of executing the care plan upon discharge. Five themes related to key processes of care, defined as care transition services and/or provider behaviors, were identified: (1) using compassionate, empathic language and gestures when communicating with patients and families; (2) anticipating patient and caregiver needs to support self-care at home ${ }_{i}(3)$ engaging in collaborative discharge planning; ${ }_{i}(4)$ providing actionable information; $_{i}$ and (5) providing uninterrupted care through the point of the patient's recovery. When participants' 


\section{Figure 1. Conceptual model of relationship between care transition outcomes desired by patients and caregivers and care transition services and provider behaviors across the care continuum.}

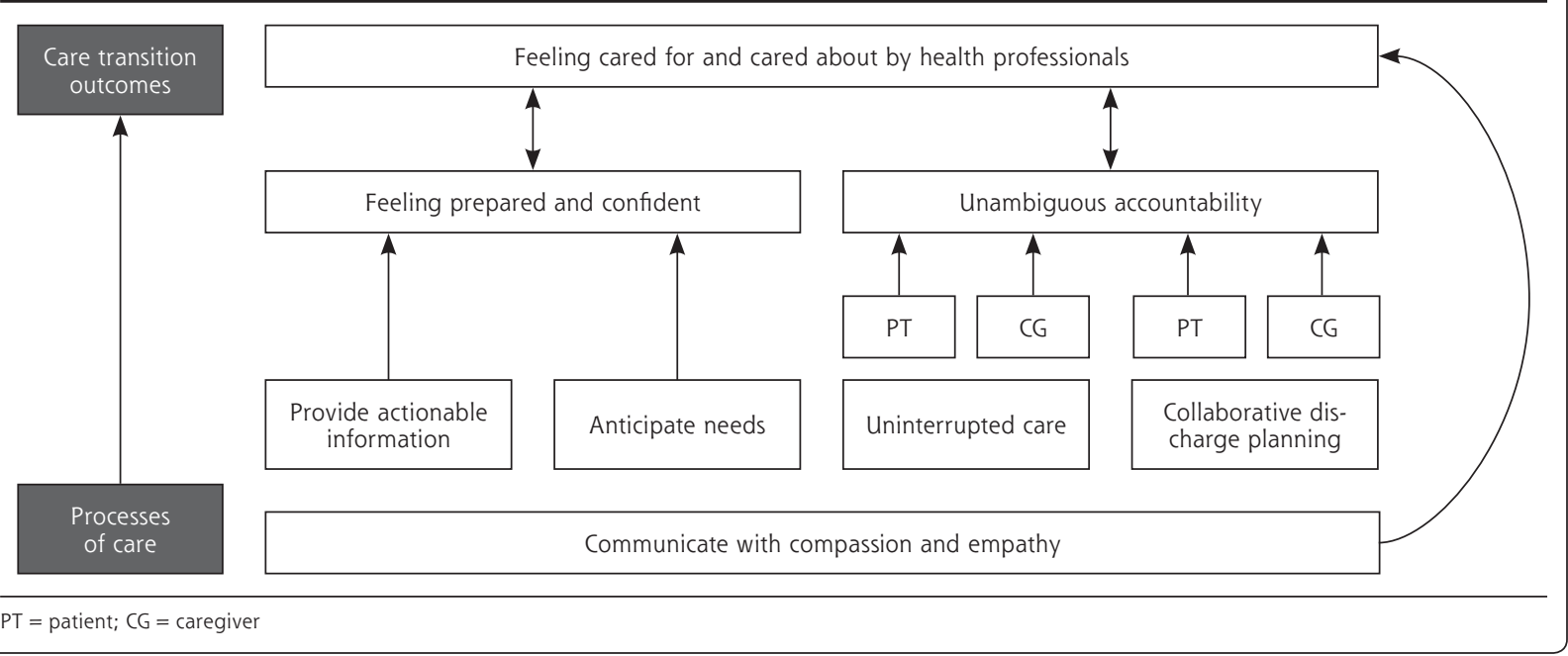

desired outcomes were realized, participants characterized care as excellent and trustworthy, caregivers experienced less distress, and reported adherence to discharge plans was increased. When desired outcomes were unmet, patients and caregivers felt deserted by the health care system, and they perceived medical care as transactional and unsafe.

We synthesized the views of patients and caregivers regarding the key elements of care transitions into a conceptual model. Figure 1 illustrates this model of how care transition services and provider behaviors (processes of care) support the desired outcomes. Overall, patients and caregivers shared similar perspectives on desired care transition outcomes. There were, however, key differences between patients and caregivers in the processes of care that were identified as essential within the themes of collaborative discharge planning and anticipating needs. With respect to collaborative discharge planning, caregivers reported that health professionals often devised discharge plans that required caregiver cooperation without eliciting caregiver input regarding the feasibility of the plan. Caregivers described the resulting transition experience as fraught with risk and distress because caregivers were unable, unwilling, or inadequately trained to carry out the plan. While this same scenario was sometimes raised by patient participants, overwhelmingly, caregivers emphasized the importance of engaging them in discharge planning.

Caregivers stressed the importance of eliciting and anticipating caregiver needs so they would be prepared and confident to deliver home care and have the resources to needed to successfully implement the discharge plan. Perspectives of patients and caregivers commonly differed on the requirements for home-based support such as home health nursing and personal care assistance. Caregivers often described how the patient declined offers from care managers to arrange for a visiting nurse or home health aide to assist with personal care or medical care at home, preferring instead that their caregiver perform those tasks. For the patient, the preference was noted as a matter of personal comfort, dignity, or to avoid having strangers in the house. Yet, according to the caregiver, the family did indeed need these additional supports and without it, the caregiver was left poorly prepared and with inadequate resources to manage safely alone.

\section{Feeling Cared For and Cared About Through the Care Transition}

Fundamental to a successful care transition is the universal need for compassionate communication and empathy, characterizing both the patient's and caregiver's experience of how care is delivered (bottom of Figure 1). This element of the care transition experience is tightly linked to the overarching goal of feeling cared for and cared about (top of Figure 1). Patients and caregivers reported poor experiences when health care teams failed to act with empathy and compassion or to work collaboratively for safe care transition. Participants unanimously expressed a wish for health professionals to sincerely convey their concern for, and commitment to, the patient's recovery and caregiver's well-being. Participants who felt a strong sense of concern from their health professionals described their doctors and nurses as attentive, supportive, compassionate, and dependable. Doctors and nurses who knew participants by name and sat down when talking with them created a feeling of presence and 
demonstrated patience and compassion. More often, however, participants reported that their need for support and empathy was overlooked, causing doubt and mistrust and causing families to step in to advocate on the patient's behalf. According to one patient (ID 036), "If it weren't for family at my hospital, you would not be cared for... because the nursing staff is not gonna $[s i c]$...go out of their way to do anything for you and when you call for them, they may or may not come." Participants revealed that when health care is delivered without care and compassion, sick people are made to feel like an inconvenience to the very individuals upon whom they rely for medical care, pain relief, nutrition, and ultimately, survival. Health care delivered in the absence of empathy is experienced as transactional. The typical consequences of dispassionate medical care were high levels of caregiver distress, deterioration in the patient's condition, nonadherence to care plans, and animosity toward the health care system. For those patients and caregivers treated by teams that delivered care transition services with caring attitudes, however, the outcomes were positive, and included trust in providers and better care plan adherence.

\section{Unambiguous Accountability From the Health Care System}

Participants desired unambiguous accountability from the health care system through the point of recovery or to a stable state of health. This outcome was described as knowing who on the health care team (ie, physician) was responsible for overseeing their care plan, and to whom they could turn for advice or medical care at any point during a care transition. When evident, this clear channel of responsibility and access to care provided needed reassurance and cultivated trust. Lack of accountability was underscored when participants were unable to name their physicians, did not have a reliable mechanism to access services or advice following discharge, and experienced clumsy transfers between hospital and community providers. The uncertainty precipitated by these experiences resulted in participants feeling unknown by their care teams, anxious about their wellbeing, and alone as they navigated between locations of care. One participant (ID 015) described the sense of abandonment when a problem arose at home with her loved one and there was nobody to call for advice, "... it's like being thrown out in the middle of a lake and [you're] expected to swim to shore and [you're] frantically searching for somebody on the other side of the lake to help you."

\section{Feeling Capable of Executing the Care Plan}

Participants felt a sense of caring from health professionals when staff took time to ensure they were prepared and capable of carrying out the care plan on their own. Participants reported a need for hospital staff to prepare and educate patients and caregivers on care plan implementation. When fully prepared, participants reported increased confidence and ability to adhere to care plans and a stronger trust in providers. Participants wished to be prepared to handle potential complications in order to avoid emotional distress and worry. Caregivers were especially concerned about being properly trained to provide home care, as described by this participant (ID 022), "[s]omebody should've advised me on what the aftercare was gonna [sic] be. If you're gonna [sic] hold me accountable to be the nurse, then you need to train me to be the nurse." One caregiver (ID 034) likened the care transition experience to "being in the wilderness," a feeling that stemmed from the recognition that patients and caregivers "don't know what they don't know" about managing medications, providing wound care, and monitoring for worrisome signs of deterioration. This uncertainty about self-care and caregiving often resulted in anxiety among patients and caused a peak in caregiver stress resulting in an overwhelming fear of inadvertently doing harm to a loved one.

\section{Anticipating Care Needs}

Participants reported it was difficult to anticipate their needs for home-based care, supplies, transportation, medications, and medical equipment following a hospital stay. One caregiver (ID 034) described her experience, "[i]t's not until you get into the wilderness at home that you realize, '[o]h my gosh, this isn't working out well.'...it's at that moment that you end up discovering the vastness of what you don't know." Participants wanted medical providers to anticipate what they will need to manage the care plan outside of a medical facility. One participant (ID 043) described how her health care team effectively anticipated her needs, "[t]hey set up the doctor's appointments [a]nd they filled the prescriptions in the pharmacy downstairs for me...they explained it line by line to $\mathrm{me}_{1} .$. that all helped." Participants described anticipating needs for successful transition to home as a fiduciary responsibility, to ensure the patient would avoid complications or adverse events, as well as preventable returns to the hospital. One patient (ID 012) expressed feeling helpless when hospital staff failed to arrange for home services he felt were critical to recovery, "[I was] sicker than I have ever been in my life...[a]nd they did not give me any type of home services. I didn't have a nurse. I didn't have a home health care aid. I didn't have anything... [a]nd then I got sick again, [and an] ambulance had to come take me [back to the hospital]." 


\section{Collaborative Discharge Planning}

Involvement in discharge planning was described as crucial and made participants feel supported by clinicians. A caregiver (ID 055) explained, "I was very glad that they included me...my involvement in the [discharge] decision making was crucial." When patients and caregivers were not involved, they felt disregarded by hospital staff and that care plans did not reflect their preferences or needs. One patient said, (ID 027) "I felt that the hospital [staff]...made decisions for me that I didn't want made and they never consulted me...it just really upset me that they made all these arrangements without asking me."

\section{Providing Actionable Information}

Participants valued timely communication about the patient's illness, diagnosis, planned treatments, and progress toward recovery. They reported feeling capable of carrying out complex discharge plans when provided actionable information, characterized as tailored and easily understood, and training on clinical skills with supervision. If staff did not provide actionable information and care training, patients and caregivers struggled to adhere to discharge plans, experienced overwhelming stress, and ultimately felt deserted by the health care team. A caregiver (ID 026) described haphazard communication with the care team, relaying "[w]e struggled for information every single day... I had to piece all of this together...I would've liked more guidance."

\section{Uninterrupted Care}

Uninterrupted care was characterized as seamless care across the care continuum, from physicians to home care providers known to the patient and caregiver. For many, continuity in care cultivated a sense of being known as a person and created greater confidence, engagement, and trust in the medical care. Participants reported that the many handoffs and lack of familiarity with patients and their caregivers that occurred during a care transition compromised the sense of feeling known by medical providers. One (ID 015) voiced his concerns, stating "hospitalists are not familiar with you whatsoever...you can't deal with your regular doctor, you have to deal with the hospitalists, and I hate that because...they're not familiar with you, they don't know your health history, anything." Overall, participants wished for fewer handoffs and preferred the same providers to be involved in their care from hospital to the outpatient and home setting.

\section{DISCUSSION}

Our study is the most comprehensive examination to date of the patient and caregiver care transition experience. Participants depicted their experiences across the care transition continuum as challenging and flawed. The positive experiences reported were characterized by continuity, compassionate care, and accountability in the health care system. Negative care transition experiences involved care perceived as transactional and anonymous, leaving participants feeling fearful and abandoned. Our findings suggest that the consequences of poor care transition experiences are substantial in that they create mistrust, anxiety, and confusion; often precipitate family conflict; and ultimately lead to inefficient care delivery, avoidable health system use, and delayed recovery. Meanwhile, the potential benefits of effective communication, continuity of care, and anticipation of patients' needs are considerable and include patient satisfaction, caregiver self-confidence, and better adherence to care plans.

Shared decision making, compassionate communication, health literacy precautions, and language translation services are well documented in the literature as integral components of care. ${ }^{15,21-23}$ Reviews of best practices during care transitions already emphasize the importance of organizing follow-up care and home services, addressing financial and psychosocial barriers during care, providing teach-back communication, ensuring medication reconciliation, and coordinating between physicians. ${ }^{24-28}$ Participants interviewed in this study repeatedly cited these transitional care components as severely lacking or inconsistently delivered, suggesting our health care system continues to struggle with demonstrating accountability to the patient and delivering satisfactory transitional care.

The diversity of our study sample constitutes a major strength of this study. The main limitation is that we were unable to directly compare the transitional care components received from the participants perspective to those actually delivered. This will be addressed in the full Project ACHIEVE analysis. Nonetheless, our findings are evident-clear accountability, care continuity, and caring attitudes are essential health care needs of patients and caregivers navigating care transitions. Serious gaps exist between the services needed and the services provided during these transitions. Health systems must learn how to better prepare patients and caregivers for care at home and design accessible channels for ongoing support in order to ensure the journey from hospital to home is safe and supports each person's recovery.

To read or post commentaries in response to this article, see it online at http://www.AnnFamMed.org/content/16/3/225.

Submitted February 15, 2017; submitted, revised, October 26, 2017; accepted November 18, 2017.

Key words: patient transfer, patient readmission, caregivers 
Funding support: This work was supported through a Patient-Centered Outcomes Research Institute (PCORI) award (Contract \#TC-1403-14049).

Acknowledgements: We would like to acknowledge the support of Ms Kimberly Parker for her editorial support and the input and advice from the Project ACHIEVE patient advisory council and the co-investigators of the Project ACHIEVE team.

Author affiliations: Department of Family Medicine, Boston Medical Center/Boston University School of Medicine, Boston, Massachusetts (Mitchell, Laurens, Weigel, Howard, Jack); School of Nursing, University of Pennsylvania, Philadelphia, Pennsylvania (Hirschman, Shaid); Department of Communication, University of Kentucky, Lexington, Kentucky (Scott); Department of Research and Evaluation, Kaiser Permanente Southern California, Los Angeles, California (Nguyen); Medical Anthropology, Boston University School of Medicine, Boston, Massachusetts (Laird); Families and Health Care Project, United Hospital Fund, New York, New York (Levine); Department of Medicine and Pediatrics, Louisiana State University Health Sciences, New Orleans, Louisiana (Davis); Telligen, Quality Improvement, Des Moines, lowa (Gass); Center for Health Services Research, University of Kentucky, Lexington, Kentucky (Li, Williams)

Disclaimer: All statements in this report, including its findings and conclusions, are solely those of the authors and do not necessarily represent the views of the Patient-Centered Outcomes Research Institute (PCORI), its Board of Governors or Methodology Committee.

Previous presentations: Study results were presented on a webinar with America's Essential Hospitals on February 17, 2016.

\section{References}

1. The Care Transitions Program - Transitional Care \& Intervention. The Care Transitions Program. http://caretransitions.org/. Accessed Oct 19, 2016.

2. Project BOOST -Better Outcome by Optimizing Safe Transitions. http:// www.hospitalmedicine.org/Web/Quality_Innovation/Implementation_ Toolkits/Project_BOOST/Web/Quality___Innovation/Implementation_ Toolkit/Boost/Overview.aspx. Accessed Oct 19, 2016.

3. Project RED. (Re-Engineered Discharge). http://www.bu.edu/fammed/ projectred/. Accessed Oct 19, 2016.

4. Transitional Care Model. http://www.nursing.upenn.edu/ncth/ transitional-care-model/. Accessed Feb 7, 2017.

5. Li J, Young R, Williams MV. Optimizing transitions of care to reduce rehospitalizations. Cleve Clin J Med. 2014;81(5):312-320.

6. Medicare C for. Baltimore MS 7500 SB, Usa M. ReadmissionsReduction-Program. https://www.cms.gov/Medicare/medicare-feefor-service-payment/acuteinpatientPPS/readmissions-reductionprogram.html. Published Apr 18, 2016. Accessed Oct 19, 2016.

7. Medicare hospital readmissions reduction program. Health Affairs - Health Policy Briefs. http://www.healthaffairs.org/ healthpolicybriefs/brief.php?brief_id=102. Accessed Oct 19, 2016.

8. Parrish MM, O'Malley K, Adams RI, Adams SR, Coleman EA. Implementation of the care transitions intervention: sustainability and lessons learned. Prof Case Manag. 2009;14(6):282-293-295.
9. Wier LM, Barrett M, Steiner C, Jiang HJ. All-Cause Readmissions by Payer and Age, 2008: Statistical Brief \#115. In: Healthcare Cost and Utilization Project (HCUP) Statistical Briefs. Rockville (MD): Agency for Healthcare Research and Quality (US); 2006. http://www.ncbi.nlm. nih.gov/books/NBK56036/. Accessed Oct 19, 2016.

10. Gerhardt G, Yemane A, Hickman P, Oelschlaeger A, Rollins E, Brennan $N$. Medicare readmission rates showed meaningful decline in 2012. Medicare Medicaid Res Rev. 2013;3(2):E1-E12.

11. Mitchell SE, Martin J, Holmes S, et al. How hospitals reengineer their discharge processes to reduce readmissions. J Healthc Qual. 2016;38(2):116-126.

12. Naylor MD, Feldman PH, Keating S, et al. Translating research into practice: transitional care for older adults. J Eval Clin Pract. 2009; 15(6):1164-1170.

13. Williams MV, Li J, Hansen LO, et al. Project BOOST implementation: lessons learned. South Med J. 2014;107(7):455-465.

14. Li J, Brock J, Jack B, et al.; Project ACHIEVE Team. Project ACHIEVE - using implementation research to guide the evaluation of transitional care effectiveness. BMC Health Serv Res. 2016;16:70.

15. Wallace LS, Rogers ES, Roskos SE, Holiday DB, Weiss BD. Brief report: screening items to identify patients with limited health literacy skills. J Gen Intern Med. 2006;21(8):874-877.

16. Silverman D. Doing Qualitative Research. 4th ed. Thousand Oaks, CASage Publications Ltd; 2013.

17. Ando $H$, Cousins $R$, Young C. Achieving saturation in thematic analysis: development and refinement of a codebook. Compr Psychol. 2014;3:03.CP.3.4

18. Guest G, Bunce $A$, Johnson L. How many interviews are enough? an experiment with data saturation and variability. Field Methods. 2006;18(1):59-82.

19. Charmaz K. Constructing Grounded Theory. 2nd ed. Thousand Oaks, CA: Sage Publications Ltd; 2014.

20. NVivo product range | QSR International. http://www.qsrinternational. com/nvivo-product. Accessed Oct 19, 2016.

21. Ha JF, Longnecker N. Doctor-patient communication: a review. Ochsner J. 2010;10(1):38-43.

22. Jackson PD, Biggins MS, Cowan L, French B, Hopkins SL, Uphold CR. Evidence summary and recommendations for improved communication during care transitions. Rehabil Nurs. 2016;41(3):135-148.

23. Travaline JM, Ruchinskas R, D'Alonzo GE Jr. Patient-physician communication: why and how. J Am Osteopath Assoc. 2005;105(1):13-18.

24. Gunderman R. Hospitalists and the decline of comprehensive care. N Engl J Med. 2016;375(11):1011-1013.

25. Dreyer T. Care transitions: best practices and evidence-based programs. Home Healthc Nurse. 2014;32(5):309-316.

26. Hansen LO, Greenwald JL, Budnitz T, et al. Project BOOST: effectiveness of a multihospital effort to reduce rehospitalization. J Hosp Med. 2013;8(8):421-427.

27. Kansagara D, Chiovaro JC, Kagen D, et al. So many options, where do we start? An overview of the care transitions literature. J Hosp Med. 2016;11(3):221-230.

28. Naylor MD, Shaid EC, Carpenter D, et al. Components of comprehensive and effective transitional care. J Am Geriatr Soc. 2017;65(6): 1119-1125. 